\title{
The Application of Constructivism to the Teaching of Intercultural Communication
}

\author{
Lin Liu $^{1} \&$ Ying Zhang ${ }^{2}$ \\ ${ }^{1}$ School of Foreign languages, University of Jinan, Jinan, China \\ ${ }^{2}$ Foreign Languages Teaching and Research Department, Qufu Normal University, Rizhao, China \\ Correspondence: Liu Lin, School of Foreign languages, University of Jinan, No. 336, West Road of Nan \\ Xinzhuang, 250022 Jinan, Shandong, China. Tel: 86-151-6884-0225. E-mail: liucherry_78@163.com
}

\author{
Received: February 1, 2014 Accepted: March 6, 2014 Online Published: April 14, 2014 \\ doi:10.5539/elt.v7n5p136 URL: http://dx.doi.org/10.5539/elt.v7n5p136
}

\begin{abstract}
Cultivating intercultural communicative competence is not a process in which teachers transmit knowledge to students, but one in which students construct their intercultural communicative competence on their own initiative. By applying the constructivist theory to the teaching of intercultural communication, the author designs a model of teaching intercultural communication and elaborates the procedure in detail. This model aims to facilitate students' construction of their intercultural communicative competence effectively.
\end{abstract}

Keywords: constructivist theory, intercultural communication, intercultural communicative competence

\section{Introduction}

Chinese Syllabus for College English Majors points out in its teaching principles that students' intercultural communicative competence should be cultivated. To be more specific, it requires that in the teaching of specialized subjects, apart from developing students' ability to use English correctly, their sensitivity and tolerance to cultural difference as well as their ability to deal with cultural difference flexibly should also be fostered, so as to adapt themselves to the increasingly prevalent international communication. Requirements for College English Teaching, issued by the Ministry of Education in January, 2004, also involve the cultivation of intercultural communicative competence as one of its teaching objectives. Therefore, intercultural communication has been included as a compulsory content in the syllabus for both English majors and non-English majors. The cultivation of intercultural communicative competence became a major concern and ultimate goal of foreign language teaching. In elementary foreign language teaching, teachers can improve students' intercultural communicative awareness and skills by way of presenting cultural knowledge and practicing communicative strategies. But the perception and command of cultural differences in non-verbal communication such as values and ways of thinking, etc. can only be achieved through the specialized subject of Intercultural Communication. Therefore, in recent years, to develop students' intercultural communicative competence, many colleges and universities have offered the subject of Intercultural Communication. Constructivist theory, which advocates that students should be the center of class and that they should construct meaning initiatively through interaction in real situations, has greatly enlightened the teaching of intercultural communication.

\section{Literature Review}

In recent years, papers concerning the teaching of intercultural communication mostly deal with specific teaching methods and strategies. For example, Carol (2010) puts forward the method of using comedy film to teach intercultural communication; Jennifer et al. (2012) suggest teaching intercultural communication through simulated conflict; Lin (2006) explores how to cultivate students'intercultural awareness and sensitivity and improve their intercultural competence; $\mathrm{Hu}$ (2006) introduces the methods of case study and discussion.

Researchers in China put more emphasis on how to develop students' intercultural communicative competence in normal English language teaching, especially in college English teaching. Yang and Zhuang (2007) suggest that the delevopment of students' intercultural communicative competence should be penetrated in the training of each English language skill.

As studies on constructivist theory being flourishing in the field of foreign language teaching, some scholars like 
Gan (2006), Zhang (2008) and Liu (2003) began to probe into its enlightenment on the teaching of intercultural communication. They stress the importance of context as well as students' initiative and collaborative learning. Theses papers merely give a theoretical account of teaching intercultural communication under the guidance of constructivist theory, without putting forward specific teaching methods. However, the detailed elaboration of a constructivist teaching model introduced in this paper makes it more operational to develop students' intercultural communicative competence.

\section{Constructivist Theory}

Constructivism, a branch of cognitive psychology, originates from the views of several psychologists and their theories, including Piaget's Cognitive Development Theory (Piaget, 1966), Vygotsky's theory of ZPD (Vygotsky, 1978) and Bruner's concept of Discovery Learning (Bruner, 1983). It reveals people's cognitive learning process and has yielded systematic teaching theories and many teaching modes.

\subsection{Constructivist Teaching Views}

Four important views on teaching are suggested by the constructivist theory. Firstly, students should occupy the cenral position in the classroom and take primary responsibility in the information-processing and meaning-constructing process, instead of being the passive receivers of external stimuli or inculcation. Learning is a process in which a student constructs meaning based on his/her own experiences and what he/she already knows (Wang, 2006, p. 6). Constructivism also believes that teachers' roles should be changed from the traditional knowledge transmitters into facilitators, organizers, guides and counselors, helping students construct and assimilate new information (Wang, 2012). Secondly, teaching should be carried out in real situations (Wu, 2006). Constructivism stresses that real situations and social communicative activities should be provided for students, so that they tend to be more motivated and effective in constructing knowledge and skills through problem-solving in relevant contexts. Thirdly, collaborative learning is of great importance (He, 1997). Constructivists believe that learners develop understanding in their own way, and different individuals perceive the same problem from different viewpoints. Therefore, cooperation among learners enhances abundant, profound and comprehensive understanding of knowledge. Communication between teachers and students as well as among students is advocated, which is helpful for students to solve problems. Fourthly, copious resources should be provided so that students can make use of a variety of information to achieve a comprehensive and incisive understanding of knowledge (Liu, 2003).

\subsection{Constructivist Teaching Modes}

Based on the above-cited views of teaching, constructivists put forward various teaching approaches and modes, with the following four being the most influential. 1) Random Access Instruction means learners can have random access to the learning objects in different ways and forms so as to gain the understanding and interpretation of the question from different aspects. 2) Scaffolding Instruction: Scaffold, which is used in architecture, is used in constructivism to illustrate vividly a kind of teaching mode: a teacher or more competent peer helps the student in his or her ZPD, Zone of Proximal Development, i.e. the difference between what a learner can do without help and what he/she can do with help. With time the teacher/peer tapers off this aid as it becomes unnecessary. In this process, teachers guide the learners to master, construct and internalize the knowledge and skills, so that learners can pursue their cognitive activities at higher levels. 3) Situated or Anchored Instruction uses typical, authentic facts and examples as anchors, leading learners to feel and experience in the real situation, to solve problems in real situation, so that learners can gain a deep perception of the objects' nature, law and their connection with other objects. This is also called problem-based instruction. 4) Top-down Instruction: Traditional Bottom-up Instruction is criticized by constructivists, who believe that it is the source of over-simplified teaching. They hold that Top-down Instruction is more effective for it firstly presents holistic tasks and provides tools for students to facilitate their understanding and solution of problems.

\section{The Application of Constructivist Theory to the Teaching of Intercultural Communication}

The objective of teaching intercultural communication is to familiarize students with the basic theories in intercultural communication, let them realize the traditions, customs, people's thinking habits, cognitive patterns and cooperative attitude in the target culture, improve students' sensitivity and tolerance to cultural difference, enable them to deal with cultural difference flexibly, as well as help them construct awareness and competence of the target culture, so that they can communicate appropriately and effectively in intercultural circumstances (Jia, 1997). Therefore, intercultural communicative competence is a comprehensive and multi-dimensional concept. Besides the knowledge dimension, there are also the dimensions of thought, behavior and even the affect and personality (Liu, 2003). However, in the process of fostering intercultural communicative competence, there is a tendency that the knowledge dimension is usually unduly highlighted. Teachers tend to merely impart 
knowledge about existing cultural facts, such as customs, etiquette, history, social institutions, or taboos. Consequently, leaners are still incapable of communicating successfully in real intercultural contexts, because those stereotyped and generalized cultural facts and behavioral patterns cannot ensure successful communication. Therefore, it is of significance for intercultural communicators to perceive and tackle reality - the ever-changing reality - rather than being merely informed and memorizing some static, highly-structured knowledge.

The four elements of constructivist theory, namely situation, collaboration, communication and meaning construction, have greatly enlightened the teaching of intercultural communication (Yang \& Jia, 2011). Before students initiatively construct their cognitive schemata, teachers should firstly provide them with a situation in which students interact with teachers, peers and effective learning tools, collaborate and communicate with others, and finally accomplish their meaning construction - the qualitative or quantitative improvement in learners' cognitive structure as a result of teaching. Teaching is meaningful only when learners' cognitive schema has been improved. Otherwise, it is meaningless.

Therefore, teachers should not merely introduce cultural background or require students to memorize some idioms, allusions or fixed communication norms, nor should they impose their own understanding of the target culture onto students. What teachers should do is to create authentic intercultural situations and guide students to experience and perceive it, encourage them to carry out exploration and facilitate their meaning construction of the target culture, thus develop their intercultural communicative competence.

Constructivist theory believes that creating situations, especially authentic ones, is a prerequisite of meaning construction. In the teaching of intercultural communication, teachers can make full use of multi-media to present geographical features, natural sceneries, historical interests, traditions and customs. By vivid and concrete means such as pictures, photos, videos and cartoons, students can directly perceive the exotic atmosphere. Those abstract and comprehensive concepts such as world view, outlook, cultural orientation, cultural adaptation and cultural shock, time and space can be either presented with written language or reproduced with cartoons. Teachers should also create an intercultural atmosphere and invent authentic pragmatic contexts, so that students can directly perceive the communicative function of language, since meaningful communication always occurs in specific contexts.

Constructivist theory suggests that social interaction plays a key role in knowledge construction. Knowledge is not brought from teachers, but achieved in a particular social-cultural context, with others', including teachers' and peers', help, using necessary learning materials and by way of meaning construction. Therefore, interactional learning is a significant proposal by constructivist theory. In teaching intercultural communication, teachers can organize students to carry out collaborative learning in a simulated situation. Classroom activities such as role-playing through situation and goals, role-playing through debate and discussion, simulation activities and improvisation, enable students to personally experience the process of intercultural communication, even cultural embarrassment and shock. Such an interaction helps students to achieve concrete communicative skills in dynamic intercultural circumstances. Besides, classroom discussion can provide students with opportunities to express their opinions and attitudes towards target culture, make their own judgment and interpretation of cultural phenomena, and finally, construct intercultural communicative competence on their own initiative.

\section{A Model of Teaching Intercultural Communication under the Guidance of Constructivist Theory}

The model, which takes Cultural Difference in Speech Act as its topic to illustrate the application of constructivist theory to the teaching of intercultural communication, is composed of seven steps: disigning environment and putting questions, putting up scaffold, independent exploration, collaborative learning, achievement presentation, effect evaluation, knowledge application.

1) Designing environment and putting questions

This step contains two activities.

Activity 1: Provide students with two pictures. Ask them to choose the best answer to the following questions according to the dialogue in each picture.

Questions about the two pictures:

1. What's the woman doing?

2. What's the man doing?

A. Greeting B. Apologizing C. Giving advice $\quad$ D. Warning

E. Complementing F. Inviting G. Complaining H. Promising I. Accepting invitation

Dialogue in picture 1: 


\section{Woman: Would you like to join us to visit the museum?}

Man: That'll be a nice way of spending a rainy and cold day like this.

Dialogue in picture 2:

Woman: Yesterday? I'm terribly sorry. I thought it was today. But I'll play tennis with you tomorrow. I promise!

Man: Promise! That's what you said last time!

The purpose of designing this activity is to arouse students' attention and interest in the topic. The vivid pictures serve to put students in an active communicative atmosphere.

Activity 2: Play a video extract which shows how people in English-speaking countries greet each other. Ask students to watch the video and review how Chinese people usually greet each other. Then make a contrast and comparison in greeting between China and English-speaking countries.

Learners constructs meaning based on his/her own experience and what they already know (Wang, 2006). Based on this belief, teachers should firstly help students to activate their prior knowledge, i.e. how Chinese people usually greet each other. Then a question is presented to the students: What are the similarities and differences in greeting between China and English-speaking countries? Such an open question can best evoke students' desire to explore new knowledge and exercise their ability to analyze and synthesize.

2) Putting up scaffold: After activating students' prior knowledge, the teacher begins to introduce to the students new concepts—speech act, explicit speech act, implicit speech act, felicity conditions-and explain with examples. This is a process of offering conceptual framework. Then the teacher provides students with adequate examples of speech act. For example:

a) A: Why don't we go out to dinner together?

B: I'm sorry. But my children will be home this evening.

b) Why don't you close the door?

c) A; It's nice to meet you. My friend told me about you. Have you lived in Seattle long?

B: No, only three months. How about you?

…...

Then the teacher asks students to classify the examples into several groups. With collective wisdom and efforts, students classify speech act into different groups, such as invitation, apology, addressing, rejection and request, etc. In this step, with teacher's scaffolding through explanation and questions, students can move to a higher level of understanding.

3) Independent exploration: Divide students into groups of four, with their different genders, characters, interests and abilities mixed together. Each group probes into one kind of speech act. The teacher shouldn't directly tell students what to do and how to do it, but help them to determine learning objectives and make a learning plan, so that each group member is to undertake a task different from others'. Take cultural difference in apology as an example: Student A goes to the library for some books to get theoretical support for their research; Student B searches the internet for articles in an academic journal written on apology; Student C looks for some video extracts as visual aids in their presentation; Student $\mathrm{D}$ goes to interview a foreigner to get his/her experience and view on cultural difference in apology. Through independent exploration, students'ability of obtaining, analyzing and applying information can be developed, the meaning of knowledge can be initiatively constructed.

4) Collaborative learning: Based on individual construction, group members gather their findings, discuss and negotiate meaning, and finally complete their research report. In this process, students think actively, participate in discussion and explain their own views. Through such an interaction with peers, learning contents and social environment, students can widen and deepen their construction of meaning and extend their skills and knowledge to the fullest potential.

5) Achievements presentation: Each group presents their research findings in class. All the group members are involved in the presentation and cooperate to reply to the queries and argument from the teacher and other groups. Through argument and communication among the whole class, students' knowledge scale is broadened. They have an overall comprehension of the cultural difference in different types of speech act, thus achieve a complete construction of knowledge. In addition, by replying to queries and argument, the presenters transform from passive receivers of knowledge into active constructors and presenters of meaning.

The above three steps are based on Vygotsky's belief that learning is a social experience which goes through 
three stages. Firstly, each individual thinks independently and gets his/her own understanding of the question at hand. Secondly, individuals construct meaning through interaction, communication and collaboration with others and get the common meaning. Thirdly, by way of recalling common meaning in a larger learning community, they finally accomplish the construction of new meaning which is shared within the community. The three stages compose the process of social construction, in which students' communicative competence can be improved and their potential can be fully displayed (Vygotsky, 1986).

6) Effect evaluation: Presentation is followed by evaluation, which can take the forms of self-evaluation, peer-evaluation, other groups' evaluation and teacher's evaluation. The objects of evaluation include forms of learning, learning effect and learners' abilities in every aspect. Reflecting and summarizing their own learning process helps to foster inventive, creative, critical learners. This is based on Ausubel's belief that learning is not only a process of learner's identifying, processing and understanding materials, but also a cognitive process of self-observation, evaluation and adaptation (Ausubel, 1968). Teachers should consciously enhance the cultivation of students' cognitive ability, direct them to constantly recognize their own abilities, characters and interests, make learning plans and choose learning strategies, help them to inspect and analyze their own learning process, so as to improve the ability of self-control, self-management and self-correction. Self-reflection can broaden students' mentality and deepen their understanding.

7) Knowledge application: Finally it is the teacher who makes a summary, highlights the important knowledge and skills, and assigns the written homework: Suppose your foreign teacher is smoking in the corridor, and you want to make a suggestion for him to give it up. How many different ways are there to express this intention? Write down as many ways as you can think of. The objective of the assignment is to enable students to use what have been learnt in real life flexibly.

\section{Conclusion}

This paper introduces a detailed model for teaching intercultural communication, with constructivist theory as its theoretical framework. By involving students in autonomous learning, initiative discovery of cultural differences and personal experience of intercultural circumstances, this model can effectively help students to form proper judgment and interpretation of target cultural phenomena and accomplish their construction of intercultural knowledge and competence.

Constructivism has launched a profound reform in the field of language teaching. Under the guidance of constructivist theory, teachers must abandon the archaic teaching conception, transforming from the traditional teaching mode in which teachers instilling knowledge into students' heads, to the new teaching mode in which students construct meaning initiatively. Teachers' roles change from authority and knowledge transmitter into the organizer of activities and facilitator of meaning construction.

Constructivist approach to the teaching of intercultural communication sets an even higher demand on teachers in the following aspects: 1) Create authentic situations to evoke student's motivation and raise their interest in learning. 2) Raise proper questions to activate students' schemata and enhance their critical thinking. 3) Design various activities to involve students in autonomous learning and collaborative learning. 4) Summarize and highlight important knowledge and skills to raise students' construction to a higher level. 5) Design interesting tasks to help students apply what they have learnt to real practice. In a word, teachers' quality is the key to effective implementation of the constructivist approach.

\section{References}

Ausubel, D. P. (1968). Educational Psychology: A Cognitive View. New York: Holt, Rinehart \& Winston.

Briam, C. (2010). Outsourced: Using a comedy film to teach intercultural communication. Busuness Communication Quarterly, 73, 383-398.

Brown, H. D. (2000). Principles of Language Learning and Teaching. Longman, Inc.

Bruner, J. S. (1983). Child's Talk: Learning to Use Language. New York: Norton.

Gan, C. (2006). On developing ICC in view of constructivism. Research in Foreign Language and Literature, 1, 49-52.

George, W. G., \& Colley, M. (2001). Designing for Learning: Six Elements in Constructivist Classrooms. California: Corwin Press, INC.

He, K. (1997). Constructivism - Theoretical foundation for the change of traditional teaching mode. E-education Research, 4. Retrieved from http://liuxiangjun163a163.blog.163.com/blog/static/420305082010235910844/ 
$\mathrm{Hu}, \mathrm{W}$. (2006). What to teach in intercultural communication and how to teach it. Foreign Languages in China, 6, 4-9.

Jennifer, P., Bradford, J., \& John, S. (2012). The flipper debate: Teaching intercultural communication through simulated conflict. Communication Teacher, $26,87$.

Jia, Y. (1997). Intercultural Communication. Shanghai: Shanghai Foreign Language Teaching Press.

Lin, J. (2006). Study on the strategies of teaching intercultural communication. Foreign Languages and Their Teaching, 4, 31-34.

Liu, L. (2004). On Cultivating Intercultural Communicative Competence in FLT (Dissertation for master's degree submitted to Qufu Normal University).

Liu, X. (2003). The cultivation of intercultural communicative competence: A constructivist view. Foreign Languages and Their Teaching, 1, 34-36. Retrieved from http://www.cnki.com.cn/Article/CJFDTotalWYWJ200301008.htm

Chinese Ministry of Education. (2000). Syllabus for College English Majors. Shanghai: Shanghai Foreign Language Education Press.

Chinese Ministry of Education. (2004). Requirements of College English Teaching.

Piaget, J. (1966). The Origin of Intelligence in Children. New York: International Universities Press.

Skehan, P. (1998). A Cognitive Approach to Language Teaching. Oxford: Oxford University Press.

Vygotsky, L. S. (1978). Mind in Society. Cambridge, Mass: Harvard University Press.

Vygotsky, L. S. (1986). Thought and Language. Cambridge: MIT Press.

Wang, J., \& Zhang, Y. (2012). Practical Application of Constructivism and Metacognition in Computer-aided College English Teaching (Vol. 43). In International Conference on Education Technology and Computer. Singapore: IACSIT Press.

Wang, Q. (2006). A Course in English Language Teaching (2nd ed.). Beijing: Higher Education Press.

$\mathrm{Wu}, \mathrm{X}$. (2006). The implication of constructivist theory to ELT. Foreign Languages and Their Teaching, 2.

Yang, W., \& Jia, N. (2011). Comments on Constructivist Learning Theory. Journal of Socialist Theory Guide, 5 , 79-82. Retrieved from http://wuxizazhi.cnki.net/Article/LLDK201105027.html

Zhang, H. (2008). On intercultural communication competences teaching and training: From the perspective of constructivism. Computer-assisted Foreign Language Education, 122, 37-40.

\section{Copyrights}

Copyright for this article is retained by the author(s), with first publication rights granted to the journal.

This is an open-access article distributed under the terms and conditions of the Creative Commons Attribution license (http://creativecommons.org/licenses/by/3.0/). 